\title{
Pinus brutia Ten. (Kızılçam) Kozalak ve Yaprak Biyomasının Boya Biyosorpsiyon/Desorpsiyon Potansiyeli
}

\author{
Fatih DEN $Z^{1}$, Şengül KARAMAN ${ }^{2}$ \\ ${ }^{1}$ Kanuni Sultan Süleyman Mesleki ve Teknik Anadolu Lisesi, Gaziantep \\ ${ }^{2}$ KSÜ, Fen-Edebiyat Fakültesi, Biyoloji Bölümü, Kahramanmaraş
}

Geliş (Received): 02.05.2014

Kabul (Accepted): 24.10.2015

\begin{abstract}
Özet: Biyosorbent rejenerasyonu ve tekrar kullanımı, biyosorpsiyon prosesini daha ekonomik hale getirmek için oldukça önemlidir. Desorpsiyon çalışmaları, biyosorpsiyon olayının mekanizmasının ortaya konulması, biyosorbentin geri kazanımı ve tekrar biyosorpsiyon prosesinde kullanımı için yapılmaktadır. Başarılı bir desorpsiyon işlemi, biyosorbentin çeşidine ve biyosorpsiyon mekanizmasına göre değişen uygun bir desorbent seçimini gerektirmektedir. Seçilen desorbentler etkili, ucuz ve zararsız olmalıdır. Bu çalışmada, kızılçam kozalak ve yaprak biyosorbentleri tarafindan biyosorplanan Basic Red 46 ve Acid Yellow 220 boyalarının biyosorbent yüzeylerinden desorpsiyonu için seyreltik $(0,1 \mathrm{M}) \mathrm{HCl}$ ve $\mathrm{NaOH}$ çözeltileri kullanılmıştır. Biyosorbentlerin boya biyosorpsiyonunda yeniden kullanım potansiyellerini değerlendirmek için ardışık biyosorpsiyon/desorpsiyon döngüsü aynı biyosorbentle üç kez tekrarlanmıştır. 0,1 M HCl kullanımı ile Basic Red 46 boyasının kozalak ve yaprak biyosorbentlerinden en düşük boya desorpsiyonu sırası ile \%90,88 ve \%95,99 olarak belirlenmiştir. 0,1 M $\mathrm{NaOH}$ kullanımı ile Acid Yellow 220 boyası için kozalak ve yaprak biyosorbentlerinden en düşük boya desorpsiyonu sırası ile \%88,37 ve \%86,79 olarak bulunmuştur. Sonuçlar, bu biyosorbentlerin ekonomik bir şekilde boya biyosorpsiyon çalışmalarında tekrar tekrar kullanılabileceğini göstermiştir.
\end{abstract}

Anahtar Kelimeler: Kızılçam, Boya, Biyosorpsiyon, Desorpsiyon

\section{Dye Biosorption/Desorption Potential of Pinus brutia Ten. (Red pine) Cone and Leaf Biomass}

\begin{abstract}
The regeneration and reuse of biosorbent is quite important in order to make the biosorption process more economical. Desorption studies were performed for elucidating the mechanism of biosorption case, recovery of biosorbent and reuse of biosorbent at biosorption process. Selection of an appropriate eluent is crucial for successful regeneration. A successful desorption process requires the selection of a proper desorbent, which depends on the type of biosorbent and the mechanism of biosorption. The selected desorbents should be effective, cheap and harmless. In this study, dilute $(0.1 \mathrm{M}) \mathrm{HCl}$ and $\mathrm{NaOH}$ solutions were employed for desorption of Basic Red 46 and Acid Yellow 220 dyes biosorbed by the cone and leaf biosorbents of red pine from the biosorbent surfaces. In order to evaluate the reuse potential of biosorbents at the dye biosorption, consecutive biosorption/desorption cycles were repeated three times with the same biosorbent. The minimum dye desorption from the cone and leaf biosorbents for Basic Red 46 by using $0.1 \mathrm{M} \mathrm{HCl}$ was defined as \%90.88 and \%95.99, respectively. For Acid Yellow 220, the minimum dye desorption from the cone and leaf biosorbents by employing $0.1 \mathrm{M} \mathrm{NaOH}$ was found as $\% 88.37$ and $\% 86.79$, respectively. The results displayed that these biosorbents as economically could be repeatedly used in the dye biosorption studies.
\end{abstract}

Key words: Red pine, Dye, Biosorption, Desorption

\section{G R Ş}

$\mathrm{Su}$ kirliliği çevre kirliliğinin önemli bir kısmını oluşturmaktadır. Su, hava ve toprakta çevre kirliliği biyolojik ve kimyasal etkenler tarafından oluşturulmaktadır. Evsel, endüstriyel, tarımsal ve diğer kullanımlar sonucunda açığa çıkan ve içinde sağlığa zararlı biyolojik ve kimyasal maddeleri barındıran sular, atık su olarak tanımlanmıştır. Atık sular, yeraltı suları, akarsu, göl ve denizlerde oluşan çevre kirliliğinin en önemli kaynaklarıdırlar. $\mathrm{Bu}$ kirlenme yalnızca su kaynakları ile sinırlı kalmayıp besin zincirine girerek gida kirlenmesine de neden olmaktadır. Atık sularda kirlenmeyi oluşturan ve buna bağlı olarak çevre kirliliğine neden olan kimyasal etmenler arasında fenoller, pestisitler, ağır metaller, hidrokarbonlar ve deterjanlar gibi maddeler vardır (Aksu, 2005; Aravindhan ve ark., 2007; Gupta ve Suhas, 2009).

Günümüzde çevre kirliliğine sebep olan spesifik kirleticilerinden biri de sentetik boyalardır. Boyarlar, başta tekstil sektörü olmak üzere çeşitli endüstri kuruluşlarında yaygın olarak kullanılmakta ve düşük miktarlarda bile kullanımı renkli atık su oluşturmaktadır (Ertaş ve ark., 2010). Tekstil ve boya üretim endüstrilerinden çıkan ve boya içeren atık sular arıtılması zor olan atık sulardan biridir. Bunun sebebi boyaların genellikle sentetik kaynaklı ve kompleks aromatik moleküler yapıya sahip olmaları ve bu yapıların boyaları daha kararlı ve biyolojik parçalanmaya karşı dirençli hale getirmesidir (Han ve ark., 2008). Tekstil ve boyama endüstrilerinde sentetik boyaların kullanımı, bu boyaların sentezinin kolay ve 
ucuz olması, oldukça dayanıklı ve doğal boyalarla karşılaştırıldı ğında renklerinin oldukça çeşitli olmaları nedeniyle giderek artmaktadır (Couto, 2009). Ticari boyaların renkleri, içerdikleri kompleks kromofor sisteminden kaynaklanmaktadır. Sentetik boyaların, güneş 1şı̆̆ına ve yıkama proseslerine oldukça dayanıklı oldukları ve ayrıca mikrobiyal parçalanmaya karşı direnç gösterdikleri bilinmektedir.

Dünya çapında yüz binin üzerinde sentetik boya ticari olarak kullanılmakta ve yıllık olarak yaklaşık yedi yüz bin ton üretim yapıldığı tahmin edilmektedir. Bu boyaların yaklaşık \%10-15'inin endüstriyel atık sularla atıldığ 1 rapor edilmiştir (Husain, 2006; Hai ve ark., 2007). Düşük konsantrasyonlarda bile boya içeren atık sular alıcı ortama deşarj edildiklerinde istenmeyen estetik problemlere yol açmaktadırlar. Boya içeren atık sular, doğal bir su ortamına karıştıkları zaman 1şı̆̆ı̀n suya girişini engelleyerek fotosentez solunum dengesi bozulmaktadır. Işık geçirgenliğini ve gaz çözünürlüğünü etkilediklerinden dolayı çözünmüş oksijen seviyesi azalmakta ve aerobik organizmalar olumsuz yönde etkilenmektedir. Bunun sonucunda ise anaerobik süreçler başlamaktadır. Bazı boyalar anaerobik parçalanmaya uğramasına rağmen parçalanma sırasında toksik ve karsinojenik aromatik aminler oluştuğundan dolayı çevre üzerine oldukça olumsuz etkiler oluşturabilmektedir. Tüm bu nedenlerden dolayı sularda doğal ekosistem ciddi şekilde bozulmaktadır (Lima ve ark., 2008; Barka ve ark., 2011).

Boyaların çevre üzerindeki olumsuz etkilerini engellemek için alıcı ortamlara deşarj edilmeden önce atık sulardan arıtılması gerekmektedir (Rauf ve ark., 2009). Literatürde tekstil atık sularının arıtılması konusunda biyosorpsiyon, kimyasal oksidasyon, kimyasal çöktürme ve filtrasyon gibi birçok teknikler mevcuttur. Son yıllarda biyosorpsiyon yöntemiyle boyarmadde giderimi büyük önem kazanmaya başlamıştır (Ferrero, 2007).

Biyosorpsiyon, endüstriyel atıkların giderimi için umut verici alternatif bir yöntemdir (Hamutoğlu ve ark., 2012) Biyosorpsiyon prosesinde boya, canlı veya ölü hücre yüzeyi üzerinde tutunur, biriktirilir veya hücre içinde akümüle edilir. Özellikle atık su toksik özellik gösteriyorsa canlı ile biyolojik arıtım uygulaması zor veya imkansız olduğunda biyosorpsiyon yöntemi avantajlı olmaktadır. Biyosorpsiyon teknolojisi diğer mevcut arıtma teknolojileri ile karşılaştırıldığında boya içeren atık sulardan renk gideriminde oldukça düşük maliyetli ve verimli bir alternatif sunmaktadır. Biyosorpsiyon teknolojisinin diğer önemli bir avantaj1, biyosorbentin yüksek verimlilikle yeniden kullanılabilmesi, yüksek seçicilik göstermesi, büyük hacimli atık sularda verimli bir şekilde uygulanabilmesi ve maliyetinin düşük olmasıdır (Bayramoglu ve ark., 2006). Biyosorpsiyonda canlı ve ölü biyokütleler kullanılabilse de, ölü biyokütleler daha çok tercih edilirler (Aksu, 2005). Ölü biyomasın kullanımına dayalı biyosorpsiyon teknolojisi toksisite sınırlamaların olmaması, besin kaynağına ihtiyaç göstermemesi ve uygun desorpsiyon metodu ile yeniden kullanılması gibi bazı önemli avantajlar sunmaktadır (Bozanta ve Ökmen, 2011; Hamutoğlu ve ark., 2012).

Biyosorpsiyon prosesinde aktif karbon ile etkin renk giderimi sağlanabilmesine rağmen oldukça pahalı oluşu boya arıtımında düşük maliyetli alternatif biyosorbent arayışını ön plana çıkarmaktadır. Bu nedenle özellikle doğada ve çevrede bol miktarda bulunan organik, inorganik maddelerin veya insani aktiviteler sonucu ortaya çıkan atıkların ya da ürün fazlalıklarının atık su arıtımında kullanımı ile hem ekonomiye hem de çevreye katkıda bulunulacaktır.

Gymnospermler içerisinde en fazla türe sahip olan Pinus cinsi kapsamında yaklaşık yüz on beş tür bulunmakta olup, bunlardan beş tanesi ülkemizde doğal olarak yayılış göstermektedir. Bu çam türleri arasında, ülkemizde en geniş yayılış gösteren kızılçam (Pinus brutia Ten.)'dır. Dünyada en fazla yayılışı Türkiye'de görülmekte olup, başlıca Akdeniz ve Ege Bölgeleri'nde doğal olarak yayılış göstermektedir ( çgen ve ark., 2006). Ülkemizde kereste kaynağı ve hoş bir görünüm sağlamak amacıyla kullanılan kızılçam, ekonomik olarak önemli bir orman ağacı türüdür. Kolay işlenmesi nedeniyle yap1 malzemesi, mobilya ve ambalaj sanayisinde kullanılmaktadır. Reçinesinden yararlanılan tek çam türüdür. Ayrıca geniş ölçüde ağaçlandırma ve yeniden ağaçlandırma programlarında kullanılmaktadır. Türkiye'de kızılçam ormanlık alanın \%27'sini oluşturmakta ve yaklaşık 6 milyon hektarlık bir alanı işgal etmektedir (Karagöz ve Demirci, 2012). Bu noktadan hareketle bu çalışmada ilk olarak tekstil endüstrisinde yaygın olarak kullanılan model Basic Red 46 ve Acid Yellow 220 boyalarının kızılçam kozalak ve yaprak biyomasıyla biyosorpsiyonu sağlanmıştır. Kızılçam kozalak ve yaprak biyosorbentleri tarafından biyosorplanan bu boyalarının biyosorbent yüzeylerinden desorpsiyonu için seyreltik $(0,1 \mathrm{M}) \mathrm{HCl}$ ve $\mathrm{NaOH}$ çözeltileri kullanılmıştır. Ardışık biyosorpsiyon/desorpsiyon döngüsü aynı biyosorbentle üç kez tekrarlanmıştır. Bu şekilde biyosorbentlerin boya biyosorpsiyonunda yeniden kullanım potansiyelleri ortaya konulmaya çalışılmıştır.

\section{MATERYAL ve METOT}

\section{Biyosorbent materyalleri}

$\mathrm{Bu}$ çalışmada biyosorbent olarak kullanılan kızılçam kozalak ve yaprakları, Burç Ormanı (Gaziantep, Türkiye)'ndan toplanmıştır. Toplanan kozalak ve yapraklar önce musluk suyu ile daha sonra da distile su ile iyice yıkanmıştır. Yıkama işleminden sonra 24 saat $70{ }^{\circ} \mathrm{C}$ 'de firında kurutulmuştur. Kuruyan biyosorbentler, bir ögütücü ile ögüüülerek partikül büyüklüğü 250-500 arasında olanlar bir elek yardımıyla diğerlerinden ayrılmıştır. $\mathrm{Bu}$ biyosorbentler, kullanılıncaya kadar desikatörde muhafaza edilmiştir. Deneyler öncesinde bu maddelere başka herhangi bir fiziksel ya da kimyasal uygulama yapılmamıştır. 


\section{Boya solüsyonları}

$\mathrm{Bu}$ çalışmada model boya olarak tekstil endüstrisinde yaygın bir şekilde kullanılan Basic Red 46 (BR 46) ve Acid Yellow 220 (AY 220) boyaları kullanılmıştır. Boyalar, lokal bir tekstil fabrikasından temin edilmiş ve ticari saflıkta olduklarından dolayı ek bir saflaştırma işlemi yapılmadan kullanılmıştır. BR 46 ve AY 220 boyalarının kimyasal yapıları, Şekil 1'de gösterilmiştir. Boyaların her biri için distile suda 500 $\mathrm{mg} \mathrm{L}^{-1}$ 'lik stok çözeltiler hazırlanmıştır. Test çözeltileri, dilüsyon yöntemi ile stok çözeltilerden istenilen derişimlerde hazırlanmıştır. Her bir deney için yeni dilüsyonlar kullanılmıştır. Çalışılan çözeltilerinin pH'ları, $0,1 \mathrm{M} \mathrm{HCl}$ ya da $0,1 \mathrm{M} \mathrm{NaOH}$ çözeltileri yardımıyla istenilen değerlere ayarlanmıştır.



Basic Red 46

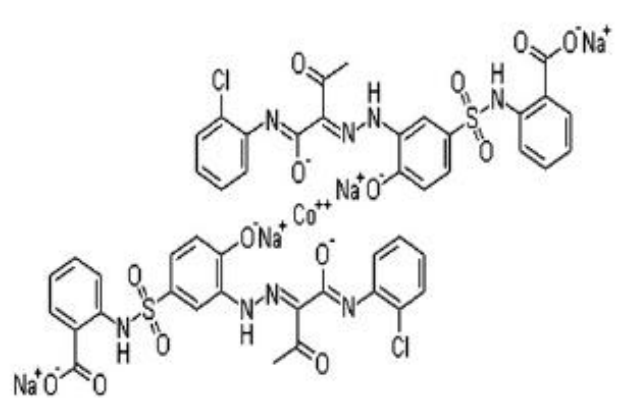

Acid Yellow 220

Şekil 1. BR 46 ve AY 220 boyalarının kimyasal yapıları

\section{FTIR ve SEM analizi}

Kızılçam kozalak ve yapraklarından hazırlanan biyosorbentlerin, FTIR spektrometresi (PerkinElmer, Spectrum 100) ile analizleri yapılarak hangi fonksiyonel gruplara sahip olduğu belirlenmiştir. Ayrıca, bu biyosorbentlerin yüzey yapısı ve morfolojisi hakkında bilgiler, bir SEM cihazı (Jeol, Jsm 6390) yardımıyla ortaya konmuştur.

\section{Biyosorpsiyon/desorpsiyon çalışmaları}

Tüm çalışmalar, bir su banyosu içerisinde kızılçam kozalak ve yaprak biyosorbentlerini kullanarak $50 \mathrm{~mL}$ BR 46 ve 50 mL AY 220 boyalarını içeren 100 mL'lik şilifli cam balonlarda gerçekleştirilmiştir. Her deney işlemi sonunda test çözeltileri, sıvı-katı ayrımının sağlanması için 5000 rpm'de 10 dakika santrifüjlenmiş ve çözelti içerisinde arta kalan boya, BR 46 için 530 nm'de ve AY 220 için 420 nm'de, bir UV-vis spektrofotometre yardımıyla analiz edilmiştir. Biyosorbentler üzerine tutunmuş boyanın miktarı daha açık bir ifadeyle biyosorpsiyon miktarı, Denklem 1 (Mittal ve ark., 2010)'de gösterilen formül yardımıyla hesaplanmıştır.

$$
q=\frac{\left(C_{\mathrm{o}}-C_{\mathrm{e}}\right) V}{M}
$$

Burada $q$, birim biyosorbent ağırlığı başına tutulan boya miktarını $\left(\mathrm{mg} \mathrm{g} \mathrm{g}^{-1}\right), C_{\mathrm{o}}$, boyanın çözeltideki başlangıç konsantrasyonunu $\left(\mathrm{mg} \mathrm{L}^{-1}\right), C_{\mathrm{e}}$, biyosorpsiyon işlemi sonrası çözeltide kalan boya konsantrasyonu (mg $\left.\mathrm{L}^{-1}\right), \quad V$, çözelti hacmini (L) ve $M$, kullanılan biyosorbent miktarını $(\mathrm{g})$ ifade etmektedir.

Biyosorbentler üzerine tutunan boyanın tekrar biyosorbent yüzeyinden desorpsiyonunu sağlamak amacıyla BR 46 boyası için $0,1 \mathrm{M} \mathrm{HCl}$ ve AY 220 boyası için $0,1 \mathrm{M} \mathrm{NaOH}$ kullanılmıştır.

Biyosorbentlerin yeniden biyosorpsiyon olayında kullanım potansiyelini belirlemek için aynı biyosorbent üç ayrı biyosorpsiyon-desorpsiyon döngüsünde kullanılmıştır. $\mathrm{Bu}$ amaçla önce biyosorbentlere boya biyosorpsiyonu işlemi yapılmıştır. Üzerine boya tutunan biyosorbentler, filtrasyon yöntemiyle ayrılmış ve üzerlerinden fazla boya moleküllerini uzaklaştırmak için yıkama yapılmıştır. Daha sonra bu biyosorbentler, 70 ${ }^{\circ} \mathrm{C}$ 'de firında kurumaya bırakılmıştır. Kuruyan biyosorbentlerin üzerine tutunmuş boyaların desorpsiyonu için biyosorbentlere, $50 \mathrm{~mL} 0,1 \mathrm{M} \mathrm{HCl}$ ve $0,1 \mathrm{M} \mathrm{NaOH}$ çözeltileri ile muamele edilmiştir. Desorpsiyon işleminden sonra yine biyosorbentler, filtrasyonla ayrılmış ve kurutma işlemi yapılarak tekrar biyosorpsiyon çalışmasında kullanılmıştır. Bu süreç üç defa tekrarlanmıştır. BR 46 ve AY 220 boyalarının biyosorbent yüzeyinden yüzde olarak desorpsiyon etkinliği, Denklem 2 (Fernandez ve ark., 2010)'de verilen formül aracılığıyla bulunmuştur.

$$
\text { Desorpsiyon }(\%)=\frac{q_{\mathrm{des}}}{q_{\mathrm{ads}}} \times 100
$$

Burada $q_{\text {ads }}$, biyosorbent tarafindan biyosorplanan boya miktarını (mg $\left.\mathrm{g}^{-1}\right)$ ve $q_{\text {des }}$, biyosorbentten desorplanan boya miktarını $\left(\mathrm{mg} \mathrm{g}^{-1}\right)$ göstermektedir.

\section{BULGULAR ve TARTIŞMA \\ FTIR analizi}

Olgun çam kozalak ve yaprakları, hücre duvarlarında selüloz, hemiselüloz, lignin, rosin ve tanen gibi maddeleri içeren epiderm ve sklerankima hücreleri ihtiva ederler. $\mathrm{Bu}$ yapilar, alkol, aldehit, keton, karboksil, fenol ve eter gibi değişik polar fonksiyonel 
gruplara sahiptirler. Bu gruplar, biyosorbent yüzeyinde boya biyosorpsiyonu için aktif bölgeler oluşturmaktadırlar (Ofomaja ve ark., 2009).

Kızılçam kozalak ve yaprak biyosorbentlerine ait FTIR spektrumları, sırasıyla Şekil 2 ve Şekil 3'te verilmiştir. $3200-3600 \mathrm{~cm}^{-1}$ bant bölgeleri, O-H gerilmesini ifade etmektedir. 2850-2950 $\mathrm{cm}^{-1}$ bant bölgeleri, C-H gerilmesini göstermektedir (Dawood ve Sen, 2012). $1731 \mathrm{~cm}^{-1}$ civarında görülen bantlar, $\mathrm{C}=\mathrm{O}$ gerilmesinin kanıtıdır. $1500-1650 \mathrm{~cm}^{-1}$ bant bölgeleri, $\mathrm{C}=\mathrm{C}$ gerilmesini belirtmektedir (Blázquez ve ark., 2012). $1430 \mathrm{~cm}^{-1}$ ve $1245 \mathrm{~cm}^{-1}$ civarlarında görülen bantlar, C-O gerilmesini gösterirken, $1300 \mathrm{~cm}^{-1}$ civarında görülen bantlar, C-N gerilmesini ifade etmektedirler. $1150 \mathrm{~cm}^{-1}$ civarında belirlenen bantlar, $\mathrm{P}=\mathrm{O}$ gerilmesini göstermektedir. $1025 \mathrm{~cm}^{-1}$ (C-O-C) ve $650 \mathrm{~cm}^{-1}$ bölgeleri arasında görülen diğer bantlar, $-\mathrm{C}-\mathrm{C}$ - ve $-\mathrm{CN}$ gerilimine atfedilmektedir (Hameed, 2009; Ofomaja ve Naidoo, 2011). Bu şekilde kozalak ve yaprak biyosorbentlerine ait spektrumlarda birçok bantın görülmesi, bu biyosorbentlerin boya biyosorpsiyonunda rol alabilecek değişik fonksiyonel gruplara sahip olduğunu göstermektedir (Ofomaja ve Naidoo, 2011).

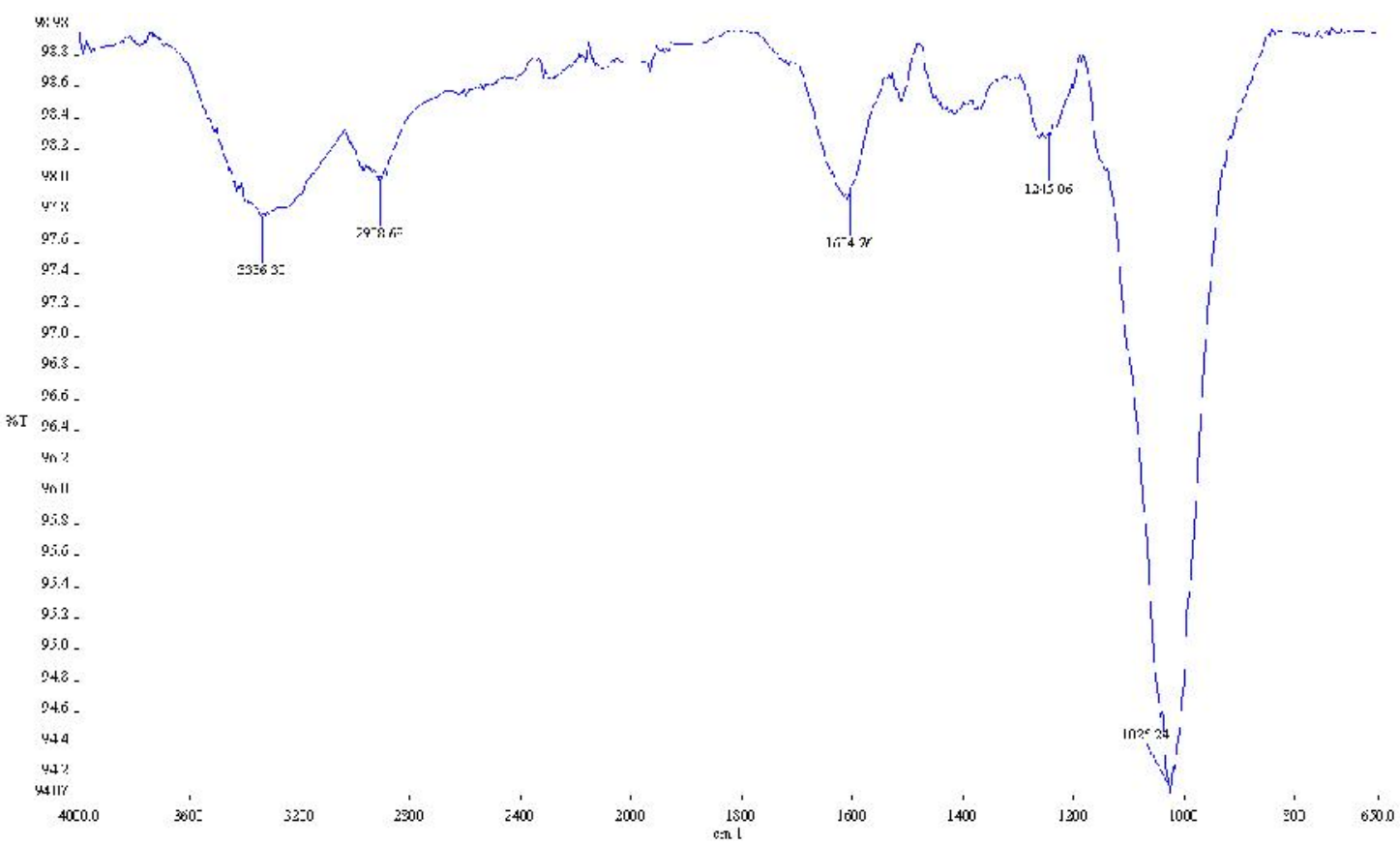

Şekil 2. Kızılçam kozalak biyosorbentine ait FTIR spektrumu

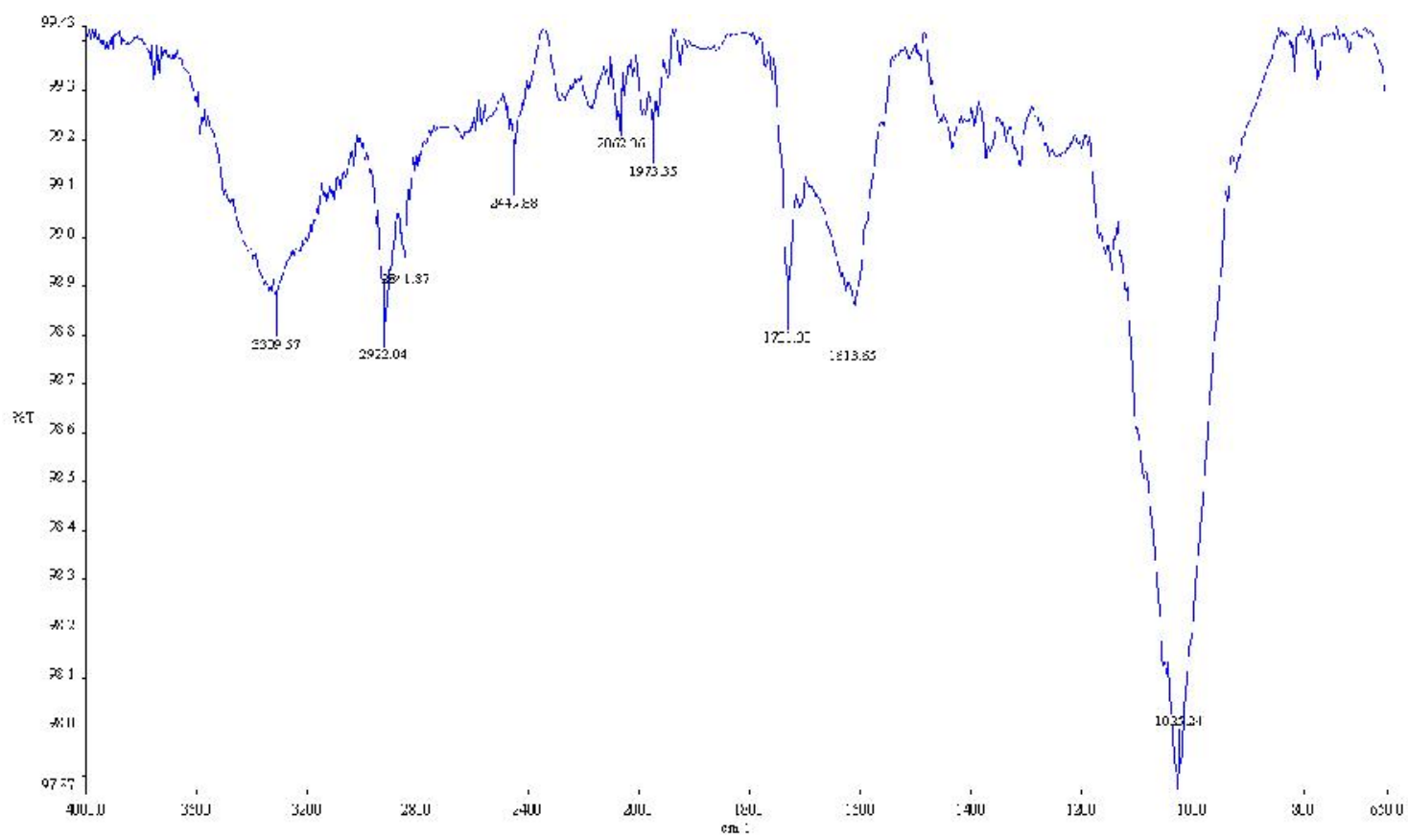

Şekil 3. Kızılçam yaprak biyosorbentine ait FTIR spektrumu 


\section{SEM analizi}

Kızılçam kozalak ve yaprak biyosorbentlerinin SEM görüntüleri, sırasıyla Şekil 4 ve Şekil 5'de gösterilmiştir. SEM analizleri, bu biyosorbentlerin pürüzlü ve çok sayıda değişik büyüklükte gözenekli bir yüzey yapısına sahip olduğuna işaret etmektedir (Ofomaja ve ark., 2013). Bu durum kozalak ve yaprakların boya biyosorpsiyonu için uygun bir biyosorbent olabileceğini ortaya koymuştur (Sen ve ark., 2011).

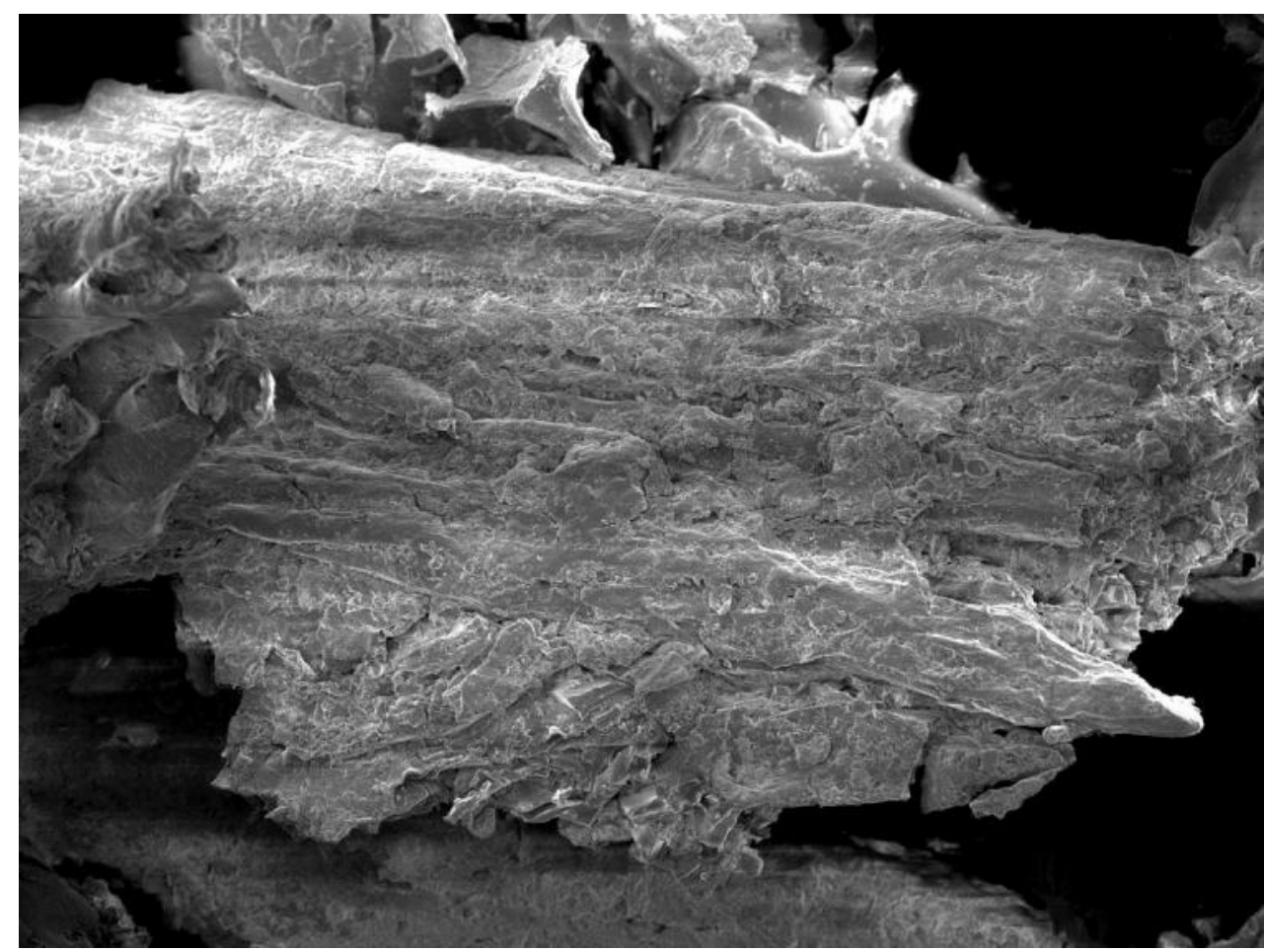

Şekil 4. Kızılçam kozalak biyosorbentine ait SEM görüntüsü (x430)



Şekil 5. Kızılçam yaprak biyosorbentine ait SEM görüntüsü (x400) 


\section{Biyosorpsiyon/desorpsiyon çalışmaları}

Biyosorbent rejenerasyonu ve tekrar kullanımı, biyosorpsiyon prosesini daha ekonomik hale getirmek için oldukça önemlidir (Cheng ve ark., 2008). Desorpsiyon çalışmaları, biyosorpsiyon olayının mekanizmasının ortaya konulması, biyosorbentin geri kazanımı ve tekrar biyosorpsiyon prosesinde kullanımı için yapılmaktadır (Fernandez ve ark., 2010; Mahmoodi ve ark., 2011). Başarılı bir desorpsiyon işlemi, biyosorbentin çeşidine ve biyosorpsiyon mekanizmasına göre değișen uygun bir desorbent seçimini gerektirmektedir. Seçilen desorbentler etkili, ucuz ve zararsız olmalıdır (Vijayaraghavan ve Yun, 2008). Bu çalışmada, kızılçam kozalak ve yaprak biyosorbentleri tarafindan biyosorplanan BR 46 ve AY 220 boyalarının biyosorbent yüzeylerinden desorpsiyonu için seyreltik $(0,1 \mathrm{M}) \mathrm{HCl}$ ve $\mathrm{NaOH}$ çözeltileri kullanılmıştır. Biyosorbentlerin boya biyosorpsiyonunda yeniden kullanım potansiyelini değerlendirmek için ardışık biyosorpsiyon/desorpsiyon döngüsü aynı biyosorbentle üç kez tekrarlanmıştır.

Kozalak biyosorbentinin BR 46 ve AY 220 boyaları için yüzde olarak desorpsiyon etkinliğgi, Çizelge 1'de gösterilmektedir. BR 46 boyası için birinci döngüde $\% 97,71$ oranında boya biyosorbent yüzeyinden uzaklaştırılırken üçüncü döngüde bu oran \%90,88'e düşmüştür. AY 220 boyası için ise birinci döngüde $\% 94,74$ oranında boya temas yüzeyinden uzaklaştırılırken son döngüde bu oran \%88,37'ye gerilemiştir. $\mathrm{Bu}$ durum muhtemelen ardişık biyosorpsiyon/desorpsiyon işlemi boyunca düşük miktarda biyosorbent kaybindan dolayı meydana gelmektedir (Cheng ve ark., 2008; Gündoğdu ve ark., 2009). Bir diğer sebep ise bir önceki döngüde biyosorbent yüzeyine tutunan bir kısım boyanın geri dönüşümsüz bir şekilde biyosorbent yüzeyindeki aktif tutunma bölgelerini ya da fonksiyonel grupları bloke etmesi olabilir (Bello ve ark., 2010).

Çizelge 1. Kozalak biyosorbentinin BR 46 ve AY 220 boyaları için yüzde olarak desorpsiyon etkinliği

\begin{tabular}{lll}
\hline Desorbent & Döngü & Etkinlik (\%) \\
\hline BR 46 için & & \\
& 1 & 97,71 \\
$0,1 \mathrm{M} \mathrm{HCl}$ & 2 & 95,61 \\
& 3 & 90,88 \\
AY 220 için & & 94,74 \\
& 1 & 90,91 \\
$0,1 \mathrm{M} \mathrm{NaOH}$ & 2 & 88,37 \\
\hline
\end{tabular}

Kızılçam yaprak biyosorbentinin BR 46 ve AY 220 boyaları için yüzde olarak desorpsiyon etkinliği, Çizelge 2'de verilmektedir. BR 46 boyası için birinci aşamada $\% 99,49$ oranında boya biyosorbent yüzeyinden giderilirken üçüncü aşamada bu oran \%95,99'a düşmüştür. AY 220 boyası için ise durum birinci aşamada \%93,55 oranında boya biyosorbent yüzeyinden uzaklaştırılırken son döngüde bu oran \%86,79'a gerileme şeklinde gerçekleşmiştir. Bu büyük olasılıkla yukarda açıklandığı gibi ardışık biyosorpsiyondesorpsiyon işlemi nedeniyle düşük miktarda biyosorbent kaybı ya da bir önceki döngüde biyosorbent yüzeyine tutunan bir kısım boyanın geri dönüşümsüz bir şekilde biyosorbent yüzeyindeki aktif tutunma bölgelerini ya da fonksiyonel grupları bloke etmesi sebebiyledir (Cheng ve ark., 2008; Liu ve ark., 2011; Sen, ve ark., 2011). Çizelgelerden de görüldüğü gibi bu biyosorbentler için en düşük boya desorpsiyonu etkinliği \%86,79 olarak belirlenmiştir. Böylece deney sonuçları, bu biyosorbentlerin düşük kapasite kayıplarıyla birlikte ekonomik bir şekilde boya biyosorpsiyon çalışmalarında tekrar tekrar kullanılabileceğine işaret etmektedir (Aksu, 2005).

Çizelge 2. Yaprak biyosorbentinin BR 46 ve AY 220 boyaları için yüzde olarak desorpsiyon etkinliği

\begin{tabular}{lll}
\hline Desorbent & Döngü & Etkinlik (\%) \\
\hline BR 46 için & 1 & 99,49 \\
& & \\
$0,1 \mathrm{M} \mathrm{HCl}$ & 2 & 96,73 \\
& 3 & 95,99 \\
AY 220 için & & \\
& 1 & 93,55 \\
$0,1 \mathrm{M} \mathrm{NaOH}$ & 2 & 87,72 \\
& 3 & 86,79 \\
\hline
\end{tabular}

\section{SONUÇ ve ÖNER LER}

$\mathrm{Bu}$ çalışmada, kızılçam kozalak ve yaprak biyosorbentleri kullanılarak BR 46 ve AY 220 boyalarının biyosorbent yüzeylerinden hızlı ve etkin bir biçimde desorpsiyon potansiyelleri ortaya konmuştur. $\mathrm{Bu}$ biyosorbentlerin, başka boyaların da biyosorpsiyon/desorpsiyon işlemlerinde kullanılarak su arıtımında yaygın olarak kullanılabilirliği araştırılmalıdır. Ayrıca, sürekli sistemlerde de biyosorpsiyon/desorpsiyon yetenekleri araştırılarak endüstriyel ölçekte ekonomik bir biyosorbent olarak kullanılabilirliği ortaya konulmalıdır.

\section{KAYNAKLAR}

Aksu, Z., 2005. Application of biosorption for the removal of organic pollutants: a review. Process Biochem. 40:997-1026.

Aravindhan, R., Rao, J.R., Nair, B.U., 2007. Removal of basic yellow dye from aqueous solution by sorption on green alga Caulerpa scalpelliformis. J. Hazard. Mater. 142:68-76.

Barka, N., Abdennouri, M., El Makhfouk, M., 2011. Removal of Methylene Blue and Eriochrome Black T from aqueous solutions by biosorption on Scolymus hispanicus L.: Kinetics, equilibrium and thermodynamics. J. Taiwan Inst. Chem. E. 42:320-326.

Bayramoğlu, G., Çelik, G., Arıca, M.Y., 2006. Studies on accumulation of uranium by fungus Lentinus sajorcaju. J. Hazard. Mater. 136:343-351. 
Bello, O.S., Adelaide, O.M., Hammed, M.A., Popoola, O.A.M., 2010. Kinetic and equilibrium studies of methylene blue removal from aqueous solution by adsorption on treated sawdust. Macedonian J. Chem. Eng. 29:77-85.

Blázquez, G., Martín-Lara, M.A., Dionisio-Ruiz, E., Tenorio, G., Calero, M., 2012. Copper biosorption by pine cone shell and thermal decomposition study of the exhausted biosorbent. J. Ind. Eng. Chem. 18:1741-1750.

Bozanta, E., Ökmen G., 2011. Biyosorpsiyon ve mikroorganizmalar. Türk Bil. Der. Derg. 4:69-77.

Cheng, W., Wang, S.G., Lu, L., Gong, W.X., Liu, X.W., Gao, B.Y., Zhang, H.Y., 2008. Removal of malachite green (MG) from aqueous solutions by native and heat-treated anaerobic granular sludge. Biochem. Eng. J. 39:538-546.

Couto, S.R., 2009. Dye removal by immobilised fungi. Biotechnol. Adv. 27:227-235.

Dawood, S., Sen, T.K., 2012. Removal of anionic dye Congo red from aqueous solution by raw pine and acid-treated pine cone powder as adsorbent: Equilibrium, thermodynamic, kinetics, mechanism and process design. Water Res. 46:1933-1946.

Ertaş, M., Acemioğlu, B., Alma, M.H., Usta, M., 2010. Removal of methylene blue from aqueous solution using cotton stalk, cotton waste and cotton dust. J. Hazard. Mater. 183:421-427.

Fernandez, M.E., Nunell, G.V., Bonelli, P.R., Cukierman, A.L., 2010. Effectiveness of Cupressus sempervirens cones as biosorbent for the removal of basic dyes from aqueous solutions in batch and dynamic modes. Bioresour. Technol. 101:9500-9507.

Ferrero, F., 2007. Dye removal by low cost adsorbents: hazelnut shells in comparison with wood sawdust. J. Hazard. Mater. 142:144-152.

Gündoğdu, A., Özdeş, D., Duran, C., Bulut, V.N., Soylak, M., Şentürk, H.B., 2009. Biosorption of $\mathrm{Pb}$ (II) ions from aqueous solution by pine bark (Pinus brutia Ten.). Chem. Eng. J. 153:62-69.

Gupta, V.K., Suhas, 2009. Application of low-cost adsorbents for dye removal - A review. J. Environ. Manage. 90:2313-2342.

Hai, F.I., Yamamoto, K., Fukushi, K., 2007. Hybrid treatment systems for dye wastewater. Crit. Rev. Env. Sci. Technol. 37:315-377.

Hameed, B.H., 2009. Grass waste: A novel sorbent for the removal of basic dye from aqueous solution. J. Hazard. Mater. 166:233-238.

Hamutoğlu, R., Dinçsoy, A.B., Cansaran-Duman, D., Aras, S., 2012. Biyosorpsiyon, adsorpsiyon ve fitoremediasyon yöntemleri ve uygulamaları. Türk Hij. Den. Biyol. Derg. 69:235-53.

Han, R., Ding, D., Xu, Y., Zou, W., Wang, Y., Li, Y., Zou, L., 2008. Use of rice husk for the adsorption of congo red from aqueous solution in column mode. Bioresour. Technol. 99:2938-2946.
Husain, Q., 2006. Potential applications of the oxidoreductive enzymes in the decolorization and detoxification of textile and other synthetic dyes from polluted water: a review. Crit. Rev. Biotechnol. 26:201-221.

çgen, Y., Kaya, Z., Çengel, B., Velioğlu, E., Öztürk, H., Önde, S., 2006. Potential impact of forest management and tree improvement on genetic diversity of Turkish red pine (Pinus brutia Ten.) plantations in Turkey. Forest Ecol. Manage. 225:328-336.

Karagöz, G., Demirci, M., 2012. Forestry property of Turkey, General Directorate of Forestry, No: 85, Ankara.

Lima, E.C., Royer, B., Vaghetti, J.C.P., Simon, N.M., DA Cunha, B.M., Pavan, F.A., Benvenutti, E.V., Veses, R.C., Airoldi, C., 2008. Application of Brazilian-pine fruit coat as a biosorbent to removal of reactive red 194 textile dye from aqueous solution, Kinetics and equilibrium study. J. Hazard. Mater. 155:536-550.

Liu, R., Zhang, B., Mei, D., Zhang, H., Liu, J., 2011. Adsorption of methyl violet from aqueous solution by halloysite nanotubes. Desalination 268:111-116.

Mahmoodi, N.M., Hayati, B., Arami, M., Lan, C., 2011. Adsorption of textile dyes on pine cone from colored wastewater: kinetic, equilibrium and thermodynamic studies. Desalination 268:117-125.

Mittal, A., Mittal, J., Malviya, A., Gupta, V.K., 2010. Removal and recovery of Chrysoidine $\mathrm{Y}$ from aqueous solutions by waste materials. J. Colloid Interface Sci. 344:497-507.

Ofomaja, A.E., Naidoo, E.B., 2011. Biosorption of copper from aqueous solution by chemically activated pine cone: A kinetic study. Chem. Eng. J. 175:260-270.

Ofomaja, A.E., Naidoo, E.B., Modise, S.J., 2009. Removal of copper (II) from aqueous solution by pine and base modified pine cone powder as biosorbent $\mathrm{J}$. Hazard. Mater. 168:909-917.

Ofomaja, A.E., Pholosi, A., Naidoo, E.B., 2013. Kinetics and competitive modeling of cesium biosortion onto chemically modified pine cone powder. J. Taiwan Ins. Chem. Eng. 44:943-951.

Rauf, M.A., Qadri, S.M., Ashraf, S., Al-Mansoori, K.M., 2009. Adsorption studies of Toluidine Blue from aqueous solutions onto gypsum. Chem. Eng. J. 150:90-95.

Sen, T.K., Afroze, S., Ang, H.M., 2011. Equilibrium, kinetics and mechanism of removal of methylene blue from aqueous solution by adsorption onto pine cone biomass of Pinus radiata. Water Air Soil Pollut. 218:499-515.

Vijayaraghavan, K., Yun, Y.S., 2008b. Biosorption of C.I. Reactive Black 5 from aqueous solution using acid-treated biomass of brown seaweed Laminaria sp.. Dyes Pigments 76:726-732. 